\title{
A INDIVIDUALIZAÇÃO DAS PAUTAS NO JORNALISMO CULTURAL IMPRESSO ${ }^{1}$
}

\section{THE INDIVIDUALIZATION OF CULTURAL PRINTED JOURNALISM AGENDAS}

\author{
Andréa Karinne Albuquerque MAIA ${ }^{2}$
}

Resumo: O jornalismo cultural está inserido no processo industrial de produção de notícias, o que torna seu conteúdo sujeito à lógica do mercado. Além desse filtro, algumas manifestações artísticas são deixadas de fora da editoria de cultura, em virtude da forma individual do jornalista, representada pela figura do editor do caderno, que sobrepõe seu interesse e gosto pessoal à noção de cultura como algo plural. Assim, a repetição no jornalismo cultural se caracteriza pela difusão de temas consagrados pelo mercado cultural. Diante do exposto, busca-se lançar um olhar sobre o jornalismo cultural a partir do conceito de cultura e da teoria do gatekeeper. Quanto à metodologia, a análise de conteúdo é usada para identificar as pautas das editorias de cultura dos jornais Correio da Paraíba e Jornal da Paraíba, no período de 15 a 31 de março de 2013.

Palavras-Chave: jornalismo cultural; pauta; teoria do gatekeeper; análise de conteúdo.

\begin{abstract}
The cultural journalism is placed in a industrial process of news production making its content bounded to the market logic. Above this filter, some artistic events are left behind of the publishing of culture as the journalist private way, represented by the notebook editor figure overlapping his or hers interests and personal liking to the culture idea as a plural something. Then, then repetition in cultural journalism is

\footnotetext{
${ }^{1}$ Trabalho apresentado no DT 1 - Jornalismo do XV Congresso de Ciências da Comunicação na Região Nordeste realizado de 12 a 14 de junho de 2013, na cidade de Mossoró-RN.

2 Mestranda do Programa de Pós-Graduação em Comunicação e Culturas Midiáticas Audiovisuais (PPGC) da Universidade Federal da Paraíba. Pesquisadora do Grupo de Pesquisa sobre o Cotidiano e o Jornalismo (Grupecj/PPGC-UFPB). MBA em Gestão Estratégica de Pessoas na Administração Pública pela Universidade Estadual da Paraíba(UEPB). Bacharel em Comunicação nas Habilitações Relações Públicas e Jornalismo (UFPB). E-mail: andreakarinne@gmail.com
} 


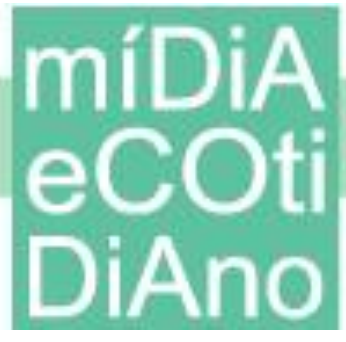

featured on dissemination of established topics by the culture market. Considering the above we are looking up to release a point of view about cultural journalism from the concept of culture and the gatekeeper theory. Regarding methods, the content analysis is applied to identify the agendas of culture publishings of the Correio da Paraíba and Jornal da Paraíba newspapers within 15 to 31 March 2013 season.

Keywords: cultural journalism; agenda; gatekeeper theory; content analysis.

\section{INTRODUÇÃO}

A mídia tem um papel fundamental na construção de discursos homogêneos a respeito de tudo que acontece na sociedade. O jornalismo cultural é um gênero responsável pelos temas relacionados à cultura em suas diversas vertentes. Apesar da influência do mercado cultural no conteúdo publicado nos cadernos de cultura, acreditase que as pautas presentes nos dois principais jornais veiculados na Paraíba são definidas, na sua maioria, a partir do gosto e interesse pessoal do editor de cultura.

Assim, busca-se analisar o fenômeno da individualização das pautas culturais, a partir da leitura do Caderno 2 e do Vida e Arte, como são chamadas respectivamente as editorias de cultura dos jornais Correio da Paraíba e Jornal da Paraíba, principais veículos impressos publicados no Estado.

A teoria da ação pessoal ou gatekeeper serve de lente para observar o fenômeno. Além disso, um breve histórico do jornalismo cultural faz-se necessário para compreender suas especificidades e evolução. Como a cultura é a principal matériaprima do gênero, percebe-se que ao particularizar as pautas, acaba-se por não reconhecer a diversidade e complexidade das culturas. Muitas vezes, essa pluralidade não ocupa espaço na mídia por não fazer parte da formação do editor, que opta por repetir os temas já consagrados pelo mercado artístico e pelas políticas culturais.

Nesse sentido, uma breve discussão sobre o conceito de cultura busca agregar valor à investigação. Por fim, como forma de aproximação da realidade procede-se a leitura dos cadernos Vida e Arte e Caderno 2, com auxílio da análise de conteúdo, que 


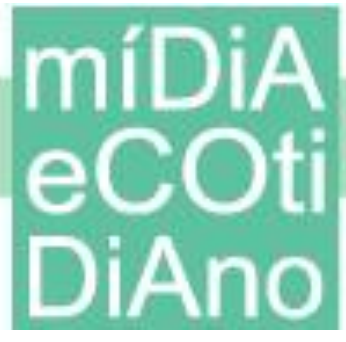

fornece os dados necessários para uma melhor compreensão do fenômeno da individualização das pautas no jornalismo cultural impresso.

\section{JORNALISMO CULTURAL}

O jornalismo cultural é responsável pela cobertura de temas relacionados à cultura em suas mais diversas e complexas vertentes. Porém, a cultura atravessa a sociedade de uma maneira tão rica, que se torna difícil tratá-la de maneira segmentada. De todo modo, essa especialidade do jornalismo tem o papel de transmitir a produção cultural para o público.

Jornalismo cultural é o ramo do jornalismo que tem por missão informar e opinar sobre a produção e a circulação de bens culturais na sociedade. Complementarmente, o jornalismo cultural pode servir como veículo para que parte desta produção chegue ao público. (GOMES, 2009, p.8)

O jornalismo cultural aborda principalmente as expressões artísticas ligadas ao cinema, música, teatro, literatura, cultura popular, dança, artes plásticas, moda e gastronomia. Bem como, a divulgação de espetáculos e entretenimento em geral. A princípio, o gênero tinha a função didática de formar adeptos às expressões artísticas consideradas mais sofisticadas, papel que vem se transformando.

[...] Originalmente tratava-se de orientar o gosto do público para socializá-lo em padrões considerados mais altos pela sociedade em geral; ensiná-lo a preferir a elegância ao espalhafato ou, pelo menos ostensivamente, Wolfgang Amadeus Mozart a Johann Strauss. Hoje, cuida-se, sobretudo de orientar um aficionado, ou pretendente aficionado, para que se insira no padrão estético mais elevado daquilo que se chama de tribo. (LAGE, 2001, p.118)

Como produto de uma empresa, o jornalismo cultural sofre influências econômicas, políticas e sociais, que vão interferir em seu conteúdo. Mas, é função do jornalista refletir a respeito das forças que se estabelecem em seu entorno, como defende Piza (2008, p.45) "a imprensa cultural tem o dever do senso crítico da avaliação de cada obra cultural e das tendências que o mercado valoriza por seus interesses, e o dever de olhar para as induções simbólicas e morais que o cidadão recebe." 


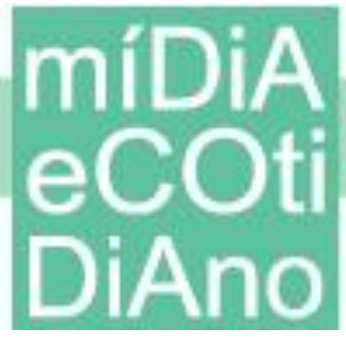

Assim, o jornalista cultural deve usar seu senso crítico, se despir dos preconceitos e não abrir mão de um texto inteligente e perspicaz, para que possa de fato contribuir com a formação do leitor.

\subsection{Breve histórico do Jornalismo cultural no mundo}

Após o Renascimento, surge o jornalismo cultural, período em que a imprensa começa se consolidar. O desenvolvimento industrial impulsiona a economia, os ideais humanistas são propagados e a opinião pública ganha força, na medida em que se forma uma promissora atividade cultural.

Em 1711, os ensaístas ingleses: Richard Steele e Joseph Addison criaram a revista diária The Spectator que é considerada um marco para o jornalismo cultural. $\mathrm{O}$ veículo tinha o objetivo de levar a filosofia para os clubes e casas de chá, abordando assuntos variados como livros, óperas, costumes, festivais de música, teatro e política. A revista possuía um estilo culto e reflexivo, e ao mesmo tempo, informal e acessível. O público alvo era o homem moderno que havia saído do campo para viver na cidade, preocupado com as novidades destinadas ao corpo e a mente. (PIZA, 2008)

O século XVIII marca a época de ouro do jornalismo cultural europeu, destacase a atuação dos escritores Jonathan Swift e Daniel Defoe, que inauguram essa fase, que contou também com nomes como Samuel Johnson, William Hazlitt, Charles Lamb, Denis Diderot, Charles Baudelaire e G.E. Lessing. Com a industrialização, no século XIX o ensaísmo e a crítica cultural tinham grande prestígio na Europa, muitos críticos como Jonh Ruskin encaravam a estética com uma espécie de religião. (PIZA, 2008)

O crítico e ensaísta Edgar Alan Poe modernizou o ambiente intelectual dos Estados Unidos pré-Guerra Civil. Enquanto que no Brasil, o jornalismo cultural ganhava força com o crítico de teatro e polemista literário Machado de Assis, além de nomes importantes como: João Veríssimo, Sílvio Romero e Araripe Jr. Nesta mesma época, Émile Zola e George Bernard Shaw, instituem um novo modelo de jornalismo cultural, com a inserção de polêmicas políticas e questões sociais. (PIZA, 2008)

No início do século XX, o gênero sofreu modificações com a inserção da reportagem, a entrevista e uma crítica de arte mais breve e participante. O jornalismo 


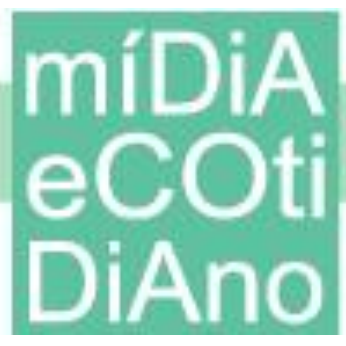

cultural adquiriu as características de sua forma moderna. Nessa fase, as revistas e os tabloides contribuíram bastante com os movimentos de vanguarda, como o surrealismo francês, o futurismo russo, o imagismo americano e o modernismo brasileiro. Os principais representantes dessa época foram: Oscar Wilde, Ezra Pound, T.S. Eliot, H.L. Mencken e Edmund Wilson. (PIZA, 2008)

A revista New Yorker, em que Wilson escreveu, foi estrela nas décadas de 1940 e 1950 e se tornou referência entre os jornalistas, tendo revelado entre os críticos mordazes com Pauline Kael na área de cinema, Lewis Mumford falando sobre arquitetura, e Arlene Croce escrevendo sobre dança. (MAGALHÃES, 2008, p. 20)

Outros dois importantes jornalistas revelados pela New Yorker foram Truman Capote, que impulsionou o jornalismo literário e John Hersey, que escreveu a reportagem "Hiroshima". A concorrente da New Yorker era a Esquire, que estava associada ao New Journalism que através de seus escritores Norman Mailer e Gay Talese misturavam história verídica e ritmo ficcional. (PIZA, 2008).

$\mathrm{Na}$ segunda metade do século $\mathrm{XX}$, os jornais diários e as revistas semanais dedicaram um espaço maior para a crítica, que assumiu um estilo mais breve, rápido e provocativo, sem perder seu poder de influência. $\mathrm{O}$ jornalismo cultural ampliou sua atuação para livros por meio de biografias e coletâneas de ensaios e críticas. Na internet encontrou um terreno fértil, através de blogs e sites. (PIZA, 2008)

\subsection{Jornalismo cultural brasileiro}

As primeiras publicações brasileiras que abordavam temas culturais são de 1808 e 1822. Tratavam sobre comércio e literatura, além de relatar interesses artísticos e descobertas científicas, a exemplo do Correio Brasiliense e da revista As variedades, ambos, editados em Londres por Hipólito José da Costa e distribuídas clandestinamente em Salvador pelo livreiro Manoel Antônio da Silva Serva. (GOMES, 2009)

No século XIX, os jornais brasileiros eram considerados veículos mais políticos que noticiosos. Contudo, a cultura esteve presente no principal jornal do Império, o 


\section{míDiA \\ eco DiAno}

Aurora Fluminense (1827 a 1839) que mantinha três seções dedicadas à cultura. (BAHIA, 1990 apud GOMES, 2009).

No início do século XX, o jornalismo cultural brasileiro ganhou força com o legado dos escritores, com destaque para Machado de Assis. Nessa época, Lima Barreto escrevia críticas culturais para o Diário de São Paulo. E a revista Cruzeiro contava com a colaboração de Mário de Andrade, José Lins do Rego, Manuel Bandeira, Vinícius de Moraes, Anita Mafaltti, Rachel de Queiroz e Di Cavalcanti.

Nessa fase literária, as publicações com textos muito longos tornaram-se inviáveis comercialmente, assim, a crônica conseguiu atrair o público. O gênero desenvolveu-se especialmente na capital carioca, por meio da combinação da cultura popular, com reflexões sobre a vida cotidiana e a cidade.

Entre 1940 e 1960, a crítica cultural ganhou força, aliando o enciclopedismo ao jornalismo, com visões políticas e apurado estilo ensaístico. Os principais representantes foram os críticos: Álvaro Lins e Otto Maria Carpeaux, ambos escreveram para o jornal Correio da Manhã em seu caderno cultural dominical, Quarto Caderno. O periódico era editado por Paulo Francis que com uma escrita afiada e humor sofisticado, conquistou tanto admiradores quanto críticos ferrenhos. Entre as presenças ilustres estavam Graciliano Ramos, Aurélio Buarque de Holanda, Carlos Drummond de Andrade, Antônio Callado, Carlos Heitor Cony, Rui Castro e Nelson Rodrigues. (PIZA, 2008)

No início dos anos 60, os veículos Última Hora, Diário Carioca e o Jornal do Brasil passaram por um processo de modernização. Este último investiu tanto na reportagem quanto no visual por meio da criação do "Caderno B".

O lendário Caderno $B$ [...] se torna o precursor do moderno jornalismo cultural brasileiro, com crônicas de Clarisse Lispector e Carlinhos de Oliveira, crítica de teatro de Bárbara Heliodora e outros trunfos; no Suplemento Dominical, Ferreira Gullar, Mário Faustino, Grunewald e os concretistas de São Paulo (Augusto e Haroldo de Campos e Décio Pignatari) faziam a cabeça da nova geração. (PIZA, 2008, p.37) 


\title{
míDiA

O projeto do JB inspira o surgimento do Suplemento Literário do Estado de São Paulo em 1956, criado por Antônio Cândido e coordenado por Décio de Almeida Prado, o periódico se destacou na época como importante mediador dos fatos culturais.

Magalhães (2008) relata que em 1969, a publicação semanal "O Pasquim" se diferenciou dos jornais diários, ao aliar o talento de sua equipe a uma linguagem mais personalista e ligada ao cotidiano. O humor tomou destaque nas páginas de personalidades como Ziraldo, Millôr Fernandes, Sérgio Augusto, Jaguar e Paulo Francis. A ditadura militar e a censura silenciaram a maior parte dos veículos, contudo, a imprensa alternativa lutava para publicar o que não podia sair no cenário nacional.

\begin{abstract}
O Pasquim e Opinião (Rio de Janeiro) e Movimento e Bondinho (São Paulo) são exemplos de publicações que aliaram em doses maiores ou menores o combate à ditadura, o humor, a denúncia e a cobertura cultural diferenciada da praticada pelos jornais diários. Alguns destes órgãos conseguiram boa vendagem, mesmo na pior fase da ditadura. Sua manutenção após a anistia, porém, se mostrou inviável devido à onda de atentados terroristas a bancas que os vendiam no começo dos anos 80. (GOMES, 2009, p.18)
\end{abstract}

Entre 1980 e 1990, dois jornais paulistas Folha de São Paulo e o antigo Estado de São Paulo, adquiriram vigor através do espírito democrático pelo qual o país passava, inovando no âmbito da cultura com os cadernos: Ilustrada e o Caderno 2 que serviram de referência para a maioria dos atuais jornais brasileiros. (PIZA, 2008)

Com a chegada da indústria cultural no início do século $\mathrm{XX}$, o jornalismo cultural passou por transformações significativas na sua forma, pois as obras de artes tornaram-se mais acessíveis e formou-se um público de artes e cultura. Assim, o crescimento do jornalismo cultural está diretamente ligado ao fortalecimento do campo cultural, inclusive com a influência das assessorias de comunicação.

Na década de 1990, estabelece-se uma nova reconfiguração, com a adesão da mídia, que passou a privilegiar assuntos com mais força no mercado, como as colunas sociais, o cotidiano das celebridades e o entretenimento, em detrimento das manifestações artísticas. (PIZA, 2008)

O indivíduo passou a cultivar o star system (indústria comercial de fabricação de mitos) não poupando nenhuma das "sete artes", com o apoio de um sistema midiático 


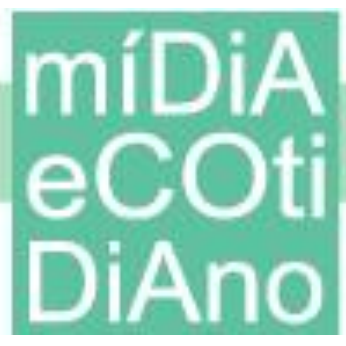

PPGMC

que faz de tudo para mantê-las enquanto são convenientes. Contudo, esses múltiplos interesses acabam por interferir na abordagem dos temas culturais. (GOMES, 2009)

\subsection{Jornalismo cultural impresso na Paraíba hoje}

Os dois principais jornais impressos publicados no Estado da Paraíba são: Correio da Paraíba e o Jornal do Paraíba. Além desses, o jornal A União é o veículo oficial do governo do Estado, que por seguir uma linha editorial muito particular quanto ao aspecto político e econômico não é objeto dessa pesquisa.

O Correio da Paraíba foi fundado em 5 de agosto de 1953 em João Pessoa-PB por Teotônio Neto, inicialmente com uma periodicidade semanal. Mas, devido ao grande sucesso tornou-se diário, onde sua principal característica era a cobertura de assuntos políticos. Segundo Araújo (1983) foi na década de 1970 que o veículo dedicou um espaço às artes com a publicação de folhetins de escritores paraibanos. A editoria de cultura do periódico chama-se Caderno 2.

O Jornal da Paraíba foi fundado em 5 de setembro de 1971 em Campina Grande-PB por um grupo de empresários. Desde o seu surgimento, o veículo possuía uma linha editorial favorável ao projeto da Ditadura Militar, instalada no Brasil em 1964. (LIMA, 2011) O Vida e Arte é o caderno de cultura publicado pelo veículo.

\section{TENTATIVA DE CONCEITUAR AS CULTURAS}

Cultura é um termo amplo e complexo para designar algo que está em constante movimento, que carrega particularidades que envolvem conhecimentos, experiências e crenças. $\mathrm{O}$ conceito de cultura se localiza entre as ações humanas e a incapacidade de descrevê-las de forma clara e precisa.

Portanto, a cultura deve ser pensada no plural, pois não existe "a cultura" e sim “culturas". Nenhuma cultura pode ser comparada a outra, tendo em vista que não há critérios capazes de confrontar o valor das culturas entre si. Além disso, os movimentos que se instalam dentro de cada cultura são construídos a partir das experiências dos indivíduos que passam a enxergar o mundo através da sua cultura. 


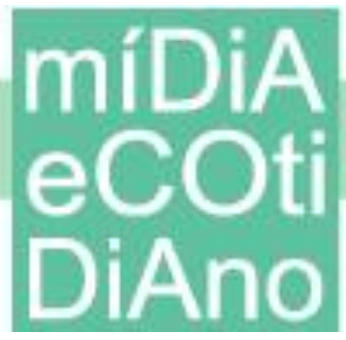

Mesmo assim, muitos teóricos formularam conceitos de cultura, o que resultou em dois grandes grupos: o antropológico e o sociológico. Para o jornalismo cultural interessa o sociológico, para o qual, a cultura é um fenômeno amplo que está presente em toda a vida social. Podendo se apresentar de forma material, através de artefatos e objetos em geral. E de forma não-material que consiste no campo das ideias, através da arte, da ética, das crenças, dos conhecimentos e dos valores.

Raymond Williams (2008) defende que de forma ampla, a cultura se refere ao modo de vida de uma comunidade, em âmbito global e totalizante. Sendo a cultura um caminho para se resolver os problemas cotidianos. E no sentido restrito, designa o processo de cultivo da mente, que pode envolver um estado mental ou espiritual.

Cultura é palavra de origem latina e em seu significado original está ligada às atividades agrícolas. Vem do verbo latino colere, que quer dizer cultivar. Pensadores romanos antigos ampliaram esse significado e a usaram para se referir ao refinamento pessoal, e isso está presente na expressão cultura da alma. (SANTOS, 1996, p.27)

A expressão mais visível da cultura está nas formas estéticas, presente nas artes como o cinema, a literatura, a pintura e a música. Mas, a cultura não é apenas uma manifestação estética, ela também é composta pelo imaginário, que por sua vez, é a soma dos elementos culturais que determinam as normas e valores sociais.

As pautas do jornalismo cultural exercem um importante papel na formação de uma concepção social de cultura.

[...] independente de suas diretrizes editoriais, é certo que a imprensa reflete e, ao mesmo tempo forma certa concepção social de cultura. Por intermédio daquilo que elege como pauta e do destaque que dá a alguns fatos em detrimento de outros, interfere no consumo social dos bens culturais. Logo, a cobertura realizada pela imprensa dinamiza e documenta o campo artístico e cultural, age na formação de públicos e fornece parâmetros de valor para a interpretação da cultura de um determinado local e época. (SEGURA; GOLIN; ALZAMORA, 2008, p.2)

\section{A AÇÃO PESSOAL NO JORNALISMO CULTURAL}

O jornalismo é uma atividade de natureza industrial, fato que permite entender que sua relação com o público perpassa por questões relacionadas ao contrato de 


\section{míDiA

comunicação midiática. No qual, são estabelecidas questões que influenciam a escolha de uma pauta em detrimento de outra.

A finalidade do contrato de comunicação midiática se acha numa tensão entre duas visadas, que correspondem, cada uma delas, a uma lógica particular: uma visada de fazer saber, ou de informação propriamente dita, que tende a produzir um objeto de saber segundo uma lógica cívica: informar o cidadão; uma visada de fazer sentir, ou visada de captação, que tende a produzir um objeto de consumo segundo uma lógica comercial: captar as massas para sobreviver à concorrência. (CHARAUDEAU, 2007, p.86, grifo do autor)

Considerando a "lógica cívica" que visa informar o cidadão, a individualização das pautas acaba por reduzir a complexidade dos assuntos culturais, ao definir o que é de interesse público a partir da visão cultural do editor do caderno.

A teoria da ação pessoal ou do gatekeeper foi criada nos anos de 1950 por David Mannig White que acompanhou durante uma semana a rotina do "Mr. Gates", um editor de um jornal norteameriacano, buscando compreender as motivações que o levaram a rejeitar as pautas que não se transformaram em notícias. (TRAQUINA, 2005)

\footnotetext{
Nesta teoria, o processo de produção da informação é concebido como uma série de escolhas onde o fluxo de notícias tem de passar por diversos gates, isto é, “ portões" que não são mais do que áreas de decisão em relação às quais o jornalista, isto é o gatekeeper, tem de decidir se vai escolher essa notícia ou não. Se a decisão for positiva, a notícia acaba por passar pelo “ portão", se não for, a sua progressão é impedida, o que na prática significa a sua "morte" porque significa que a notícia não será publicada, pelo menos nesse órgão de informação. (TRAQUINA, 2005, p. 150, grifo do autor)
}

Assim, a teoria do gatekeeper fundamenta-se em estudos focados na pessoa do jornalista, que seleciona as notícias de maneira subjetiva, a partir de suas experiências, valores e expectativas, sem considerar os constrangimentos organizacionais sofridos pelo profissional. (SOUSA, 2002).

Nesse sentido, as críticas à teoria do gatekeeper se fundamentam no fato de deixar de considerar outras forças de influências na seleção das notícias, sobretudo as organizacionais. Como afirma Traquina $(2005$, p.151) “[...] é uma teoria que privilegia 


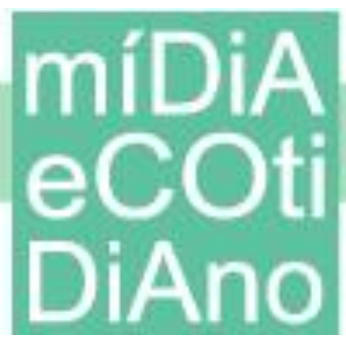

apenas uma abordagem micro-sociológica, ao nível do indivíduo, ignorando por completo quaisquer fatores macro-sociológicos [...]"

Apesar das restrições da teoria do gatekeeper, a ação pessoal do editor no jornalismo cultural é algo muito presente. O jornalista exerce uma liberdade limitada, na medida em que existem outras forças de influência no processo, depois de vencidas essas barreiras, o editor seleciona as pautas a partir da sua formação cultural. Como ratifica Sousa (2002, p. 45) “as notícias possuem sempre a marca da ação pessoal de quem as produz, embora temperada por outras formas conformadoras".

Enfim, "as notícias são um artefato construído pela interação de várias forças, que podemos situar ao nível das pessoas, do sistema social, da ideologia, da cultura, do meio físico e tecnológico e da história." (SOUSA, 2002, p.17). A conjunção dessas forças resulta na repetição do jornalismo cultural.

O que diferencia o perfil de cada caderno de cultura não é só a linha editorial do jornal. A ação pessoal do editor estabelece critérios subjetivos de escolhas, definindo a abrangência temática das pautas, sem necessariamente, lançar mão dos espaços destinados aos temas culturais já consagrados pelo mercado.

\section{METODOLOGIA}

A investigação busca perceber como ocorre o fenômeno da individualização das pautas nas editorias de cultura dos jornais Correio da Paraíba e Jornal da Paraíba. Para isso, as notícias foram classificados em categorias artísticas/culturais.

$\mathrm{Na}$ pesquisa, foram consideradas apenas as matérias assinadas pelos jornalistas das editorias de cultura. Não sendo objeto da análise notas, matérias de agências, colunas sociais e de opinião, programação da TV e agenda cultural, por terem uma relação de autonomia diferenciada com o jornal.

A análise de conteúdo foi adotada como ferramenta metodológica, que pode ser definida como sendo

Um conjunto de técnicas de análise de comunicação visando a obter, por procedimentos sistemáticos e objetivos de descrição do conteúdo das mensagens, indicadores (quantitativos ou não) que permitam a inferência de conhecimentos relativos às condições de produção/recepção destas mensagens. (BARDIN, 1979, p. 42) 


\section{míDiA

O material empírico é formado pelas matérias dos cadernos de cultura dos jornais Correio da Paraíba e Jornal da Paraíba publicadas no período de 15 a 31 de março de 2013. No entanto, as datas 18 e 25 de março não fazem parte do estudo, pois são dias de segunda-feira, nos quais os cadernos não circulam. O corpus é composto por 15 edições do Caderno 2 e 15 edições do Vida e Arte, totalizando 30 cadernos.

Por meio da análise de conteúdo, as matérias foram classificadas em categorias temáticas. Como as matérias são assinadas, os jornalistas responsáveis são nomeados no estudo pelas letras: A, B, C, D, E, F, G e H visando preservar a identidade dos mesmos.

\subsection{Análise e descrição dos resultados}

Nas 15 edições analisadas do Caderno 2 do jornal Correio da Paraíba foram publicadas 51 matérias, distribuídas em oito categorias temáticas, produzidas por cinco jornalistas diferentes. O Gráfico 1 mostra que quatro temas estão presentes numa maior quantidade, são eles: teatro, literatura, música e cinema. Essas quatro categorias juntas somam 44 matérias, o que corresponde aproximadamente a $86 \%$ do conteúdo analisado, contra apenas sete matérias que tratam dos quatro demais temas.

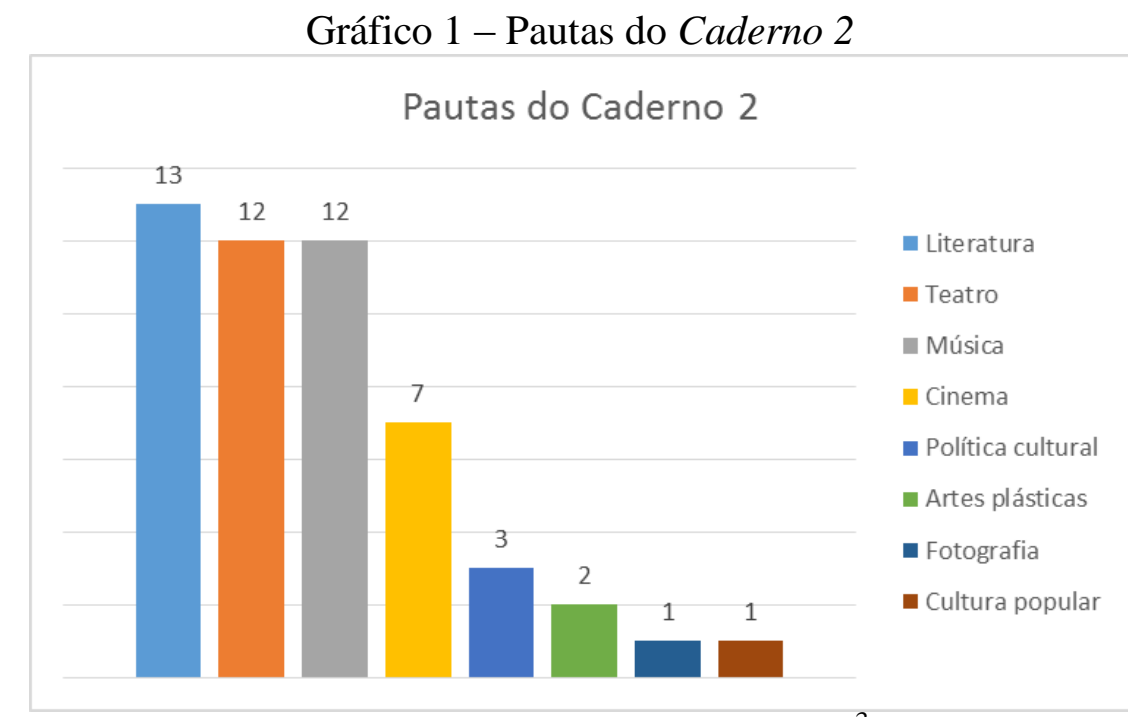

Fonte: Pesquisadora, $2013^{3}$

\footnotetext{
${ }^{3}$ Gráfico elaborado pela pesquisadora a partir do conteúdo do Caderno 2 do jornal Correio da Paraíba, publicado nos período de 15 a 17, 19 a 24 e 26 a 31 de março de 2013.
} 
Apesar das categorias música e cinema serem temas constantes nos cadernos de cultura, por estarem atrelados às políticas de mercado e atraírem um grande público. A literatura é responsável por 13 das 51 matérias, enquanto que o teatro e a música empatam com 12 notícias, e a categoria cinema com sete matérias. Esses dados apontam uma preferência do editor pela literatura.

As quatro categorias com menor representatividade juntas ocupam quase $14 \%$ do conteúdo do Caderno 2. Esse aspecto reforça a repetição no jornalismo cultural, que por vezes, não abre espaço para a pluralidade da cultura.

A Tabela 1 apresenta um panorama geral das pautas do Caderno 2, com ênfase no aspecto individual, a partir das categorias abordadas pelos jornalistas, estes estão representados através das letras $\mathrm{A}, \mathrm{B}, \mathrm{C}, \mathrm{D}$ e E.

Tabela 1 - Pautas das Matérias do Caderno 2

\begin{tabular}{|l|c|c|c|c|c|c|}
\hline \multirow{2}{*}{$\begin{array}{l}\text { Categorias } \\
\text { temáticas }\end{array}$} & \multicolumn{5}{|c|}{ Jornalistas responsáveis } & \multirow{2}{*}{ Total } \\
\cline { 2 - 6 } & $\mathrm{A}$ & $\mathrm{B}$ & $\mathrm{C}$ & $\mathrm{D}$ & $\mathrm{E}$ & \\
\hline Literatura & - & 9 & 4 & - & - & 13 \\
\hline Teatro & - & 8 & 4 & - & - & 12 \\
\hline Música & 2 & 4 & 1 & 3 & 2 & 12 \\
\hline Cinema & - & 5 & 2 & - & - & 7 \\
\hline Política cultural & - & 2 & 1 & - & - & 3 \\
\hline Artes plásticas & - & 2 & - & - & - & 2 \\
\hline Fotografia & - & 1 & - & - & - & 1 \\
\hline Cultura popular & - & - & - & 1 & - & 1 \\
\hline Total & 2 & 31 & 12 & 4 & 2 & 51 \\
\hline
\end{tabular}

Diante do exposto, percebe-se que a maioria dos jornalistas, três dos cinco dedicaram-se a um número limitado de temas. O jornalista $\mathrm{D}$ produziu quatro matérias que envolvem apenas as categorias música e cultura popular. Os profissionais A e E produziram matérias de uma única categoria. Enquanto que, a minoria, B e C escreveram sobre uma maior diversidade de temas, respectivamente sete e cinco.

As informações visualizadas na Tabela 1 permite inferir que há uma relação entre a multiplicidade temática e a produção individual. Tendo em vista que, tanto $\mathrm{B}$

\footnotetext{
${ }^{4}$ Tabela elaborada pela pesquisadora a partir do conteúdo do Caderno 2 do jornal Correio da Paraíba, publicado nos período de 15 a 17, 19 a 24 e 26 a 31 de março de 2013.
} 


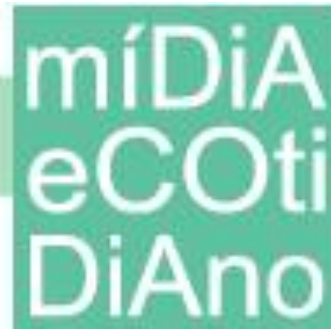

quanto $\mathrm{C}$ tiveram uma produção substancialmente maior que os demais, juntos foram responsáveis por $84 \%$ do conteúdo. Enquanto que o jornalista B sozinho produziu 31 matérias, ou seja, mais de $60 \%$ da amostra. Enquanto que A, D e E são responsáveis juntos por apenas oito das 51 matérias produzidas.

O Caderno 2 durante o período analisado seguiu à tendência das editorias de cultura, disponibilizando um maior espaço para as categorias música, cinema, literatura e teatro, em detrimento das demais que aparecem numa menor quantidade ou nem sequer foram representadas. Apesar disso, a julgar pelos números, o editor do Caderno 2 tem uma maior inclinação pela literatura e pelo teatro.

A editoria de cultura do Jornal da Paraíba, o caderno Vida e Arte publicou nas 15 edições analisadas um total de 77 matérias, de autoria de três jornalistas, com pautas que abrangem noves categorias, como ilustra o Gráfico 2.

Gráfico 2 - Pautas do Vida e Arte

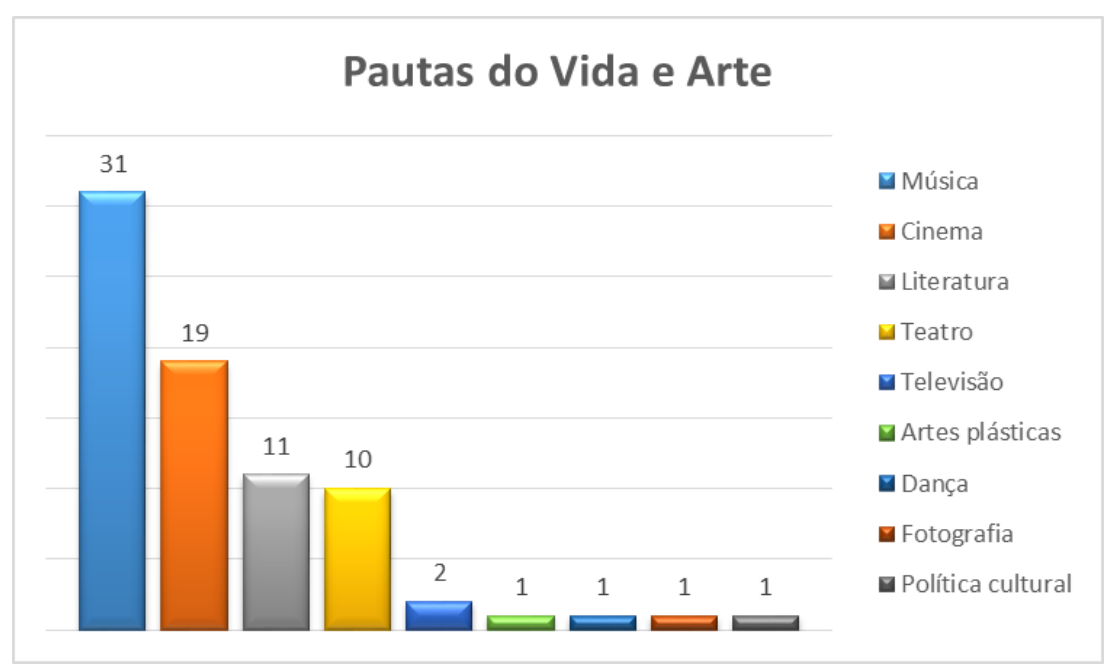

Fonte: Pesquisadora, $2013^{5}$.

Semelhante ao Caderno 2, as quatro categorias com maior presença no Vida e Arte são música, cinema, literatura e teatro, juntas essas categorias são responsáveis por aproximadamente $92 \%$ do conteúdo em análise. No entanto, o grande destaque é a

\footnotetext{
${ }^{5}$ Gráfico elaborado pela pesquisadora a partir do conteúdo caderno Vida e Arte do Jornal da Paraíba,
} publicado nos período de 15 a 17, 19 a 24 e 26 a 31 de março de 2013. 


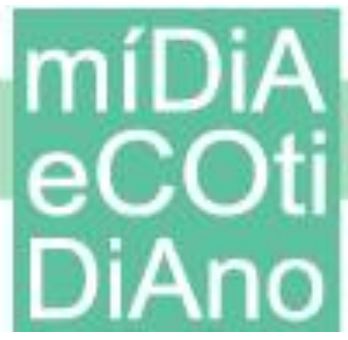

música, categoria responsável por aproximadamente $40 \%$ de todas as matérias, seguida pelo cinema com cerca de $25 \%$ da amostra.

O teatro com quase $13 \%$ e a literatura com cerca de $14 \%$, apesar de figurarem entre os quatro temas de maior representatividade, possui uma presença pouco expressiva em comparação às categorias música e cinema, que além de contarem com as estratégias de mercado disponíveis, são eleitos como carro-chefe pelo editor do caderno.

Os profissionais responsáveis pela editoria são representados na Tabela 2 através das letras: F, G e H.

Tabela 2- Pautas do Vida e Arte

\begin{tabular}{|l|c|c|c|c|}
\hline \multirow{2}{*}{\multicolumn{1}{c|}{ Pautas }} & \multicolumn{3}{|c|}{ Jornalistas Responsáveis } & \multirow{2}{*}{ Total } \\
\cline { 2 - 4 } & $\mathrm{F}$ & $\mathrm{G}$ & $\mathrm{H}$ & \\
\hline Música & 6 & 5 & 20 & 31 \\
\hline Cinema & 6 & 2 & 11 & 19 \\
\hline Literatura & 10 & - & 1 & 11 \\
\hline Teatro & 10 & - & - & 10 \\
\hline Artes plásticas & - & - & 1 & 1 \\
\hline Dança & 1 & - & - & 1 \\
\hline Fotografia & 1 & - & - & 1 \\
\hline Política cultural & 1 & - & - & 1 \\
\hline Televisão & 1 & - & 1 & 2 \\
\hline Total & 36 & 7 & 34 & $\mathbf{7 7}$ \\
\hline
\end{tabular}

As pautas do jornalista $\mathrm{F}$ alcançam oito categorias, das quais a metade (música, teatro, literatura e cinema) contam com mais de uma matéria, ele obteve o maior desempenho, com 36 das 77 matérias, o que equivale a quase $47 \%$ do conteúdo do caderno. O segundo lugar é do jornalista $\mathrm{H}$, que foi responsável por 34 notícias que abordam cinco categorias, sendo 20 de música, 11 de cinema e uma para cada tema: literatura, artes plásticas e televisão. Tais número expressam sua preferência pelos temas música e cinema. $\mathrm{O}$ jornalista $\mathrm{G}$ tem a menor produção, apenas sete das 77 matérias, que abordam apenas as categorias música e cinema.

\footnotetext{
${ }^{6}$ Tabela elaborada pela pesquisadora a partir do conteúdo do caderno Vida e Arte do Jornal da Paraíba, publicado nos período de 15 a 17, 19 a 24 e 26 a 31 de março de 2013.
} 


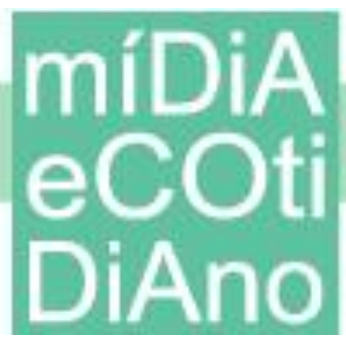

PPGMC

Tanto no Caderno 2 quanto no Vida e Arte, as categorias música, cinema, teatro e literatura são maioria, o que demonstra a existência do fenômeno da repetição no jornalismo cultural, resultante do espaço destinado aos temas consagrados pela mídia.

Além disso, os temas cinema e música são manifestações que dispõem de um grande aparato publicitário, que garante o retorno dos altos investimentos de produção. Em linhas gerais, a literatura e o teatro dependem muito mais de recursos oriundos de políticas culturais.

Enfim, o que diferencia o conteúdo das duas editorias e reforça a individualização das pautas é a quantidade das quatro categorias preponderantes. Nesse sentido, o Vida e Arte fortalece as categorias que estão mais ligados ao mercado: cinema e música. E o Caderno 2 investe mais em literatura, seguido pelo teatro e a música.

O maior número de pautas sobre literatura em comparação ao cinema é resultante de uma maior liberdade de escolha do editor, que sofre uma pressão menor do mercado para publicá-las, ratificando assim, o fenômeno da individualização das pautas.

\section{CONCLUSÃO}

A presente investigação não tem a pretensão de ser uma análise acabada e definitiva sobre o jornalismo cultural impresso, sobretudo por tratar de um período limitado de tempo. Sendo apenas um ponto de partida para compreender o fenômeno da individualização das pautas, baseado na observação dos cadernos de cultura dos dois principais jornais paraibanos.

Apesar da teoria do gatekeeper ser considerada por muitos teóricos como ultrapassada, a ação pessoal do editor de cultura exerce uma grande influência na produção de notícias. A ação pessoal está presente no momento em que o jornalista opta por escrever textos que atendam ao seu gosto e interesse pessoal, em detrimento de matérias que abordam outros temas.

De certa forma, o leitor torna-se dependente do gosto pessoal dos jornalistas culturais, que deixam de cumprir sua função social, para ser uma espécie de "juiz" do que deve ser ou não apreciado pelo público. Principalmente, levando-se em conta a 


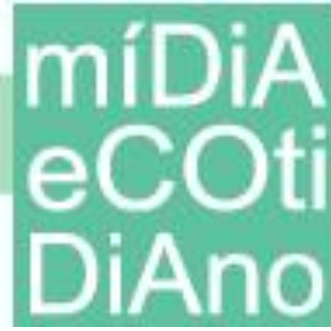

pluralidade e complexidade do conceito de cultura amplamente estabelecido nas sociedades.

Enfim, a individualização das pautas restringe a multiplicidade de informações culturais que é transmitida aos leitores. Ao mesmo tempo em que, os profissionais que tendem a escrever sobre diversos temas, acabam por produzir mais do que os jornalistas que limitam suas pautas a temas costumeiros.

\section{REFERÊNCIAS}

ARAÚJO, Maria de Fátima S. História e ideologia da imprensa na Paraíba: dados históricos e técnicos, João Pessoa: A União Cia. Editora, 1983.

BARDIN, Laurence. Análise de conteúdo. Lisboa: Edições 70, 1979.

CHARAUDEAU, Patrick. Discurso das mídias. São Paulo: Contexto, 2007.

GOMES, Fábio. Jornalismo cultural. Brasileirinho Produções: 2009. Disponível em:

<http://www.jornalismocultural.com.br/jornalismocultural.pdf>Acesso em: 18 abr. 2013.

LAGE, Nilson. Reportagem: Teoria e técnica de entrevista e pesquisa jornalística. 6.ed. Rio de Janeiro: Record, 2001.

LIMA, Luciano Mendonça de. História e poder nas páginas de um jornal: 1971/2011. Artigo postado no site da Universidade Federal de Campina Grande, no hiperlink Mais notícias. Disponível em: <http://www.ufcg.edu.br/prt_ufcg/assessoria_imprensa/mostra_noticia.php? codigo=12875> . Acesso em 15 Abr. 2013.

MAGAlHÃES, Marina. Polarizações do jornalismo cultural. João Pessoa: Marca de Fantasia, 2008.

PIZA, Daniel. Jornalismo cultural. 3.ed. São Paulo: Contexto, 2008.

SANTOS, José Luiz dos. O que é Cultura? 16 ed. São Paulo: Brasiliense, 1996.

SEGURA, Aylton; GOLIN, Cida; ALZAMORA, Geane. O que é jornalismo cultural. In: Adriana AZZOLINO et al.. (Org.). Mapeamento do ensino de jornalismo cultural no Brasil em 2008. São Paulo: Itaú Cultural, 2008, p. 70-80. 


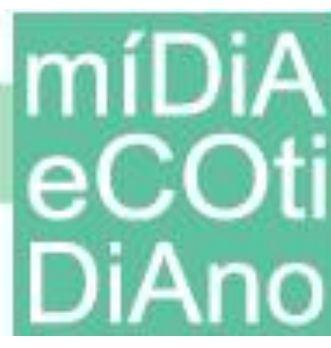

SOUZA, Jorge Pedro. Teorias da notícia e do jornalismo. Chapecó: Argos, 2002.

TRAQUINA, Nelson. Teorias do Jornalismo - Porque as Notícias São Como São V. 1. Florianópolis: Insular, 2005.

WILLIAMS, Raymond. Cultura. 3. ed. Rio de Janeiro: Paz e Terra, 2008. 